\title{
Estimasi Risiko
}

\section{Investasi Saham di Sektor Keuangan Menggunakan Metode ARCH-GARCH}

\author{
Ayu Enitasari Aprilia, Soehardjoepri, dan Farida Agustini Widjajati \\ Departemen Matematika, Fakultas Matematka dan Ilmu Pengetahuan Alam, Institut Teknologi \\ Sepuluh Nopember (ITS) \\ e-mail: agustini.farida54@gmail.com
}

\begin{abstract}
Abstrak - Dalam berinvestasi, tentunya seorang investor tidak hanya memikirkan besarnya return saja melainkan juga harus emikirkan besar risiko yang diterima. Adanya risiko dalam berinvestasi saham, menuntut investor untuk melakukan analisis terhadap berbagai saham sesuai dengan kondisi terkini. Keberhasilan investor dalam melakukan investasi ditentukan oleh keahlian investor tersebut dalam mengestimasi dan mengelola risiko. Salah satu cara untuk mengestimasi risiko adalah dengan menggunakan Value at Risk (VaR). VaR memiliki hubungan erat dengan model ARCH-GARCH, yang sering digunakan jika terjadi heteroskedastisitas pada data log return. Dari analisis data log return yang dilakukan, model mean yang sesuai untuk saham Bank Central Asia Tbk (BBCA) adalah ARMA ([3],[3,32]) dan model variannya adalah ARCH(1). Sedangkan untuk saham Bank Negara Indonesia Tbk (BBNI) model mean yang sesuai adalah ARMA ([1],[28]) dan model variannya adalah ARCH(3). Perhitungan estimasi risiko dengan menggunakan simlasi Monte Carlo pada saham BBCA menghasilkan nilai VaR rata-rata sebesar Rp. 21.181.676,00 sedangkan untuk saham BBNI adalah Rp. 13.165.936,00.
\end{abstract}

Kata Kunci-ARCH-GARCH, ARMA, log return, VaR.

\section{PENDAHULUAN}

$\mathrm{K}$ ONDISI perekonomian suatu negara cenderung berfluktuasi dari tahun ke tahun. Salah satu cara yang dapat digunakan untuk mengetahui perkembangan perekonomian suatu negara adalah melihat perkembangan pasar modal sebagai leading indicator perekonomian [1]. Adanya pasar modal memberikan sarana alternatif bagi masyarakat maupun perusahaan untuk menginvestasikan uangnya, dengan harapan mendapatkan keuntungan. Sehingga bisa digunakan sebagai pengembangan usaha atau penambahan modal kerja.

Dalam melakukan investasi, tentunya seorang investor akan memilih menginvestasikan dana pada perusahaan yang memberikan rasa aman pada investasinya. Pada tingkat keamanan tersebut, seorang investor memiliki ekspektasi pengembalian (return) yang sebesar-besarnya pada tingkat risiko tertentu. Risiko adalah besarnya penyimpangan antara tingkat pengembalian yang diharapkan (expected return) dengan tingkat pengembalian aktual (actual return). Saham memiliki karakteristik high risk-high return yang artinya saham merupakan surat berharga yang memberikan peluang keuntungan yang tinggi namun juga memiliki resiko tinggi.

Oleh sebab itu, perlu adanya alat ukur tingkat resiko agar investor aman dalam berinvestasi dan terhindar dari kerugian. Sejak pengenalannya pada tahun 1994 oleh J.P. Morgan
Riskmetrics, Metode VaR (Value at Risk) merupakan metode yang sangat popular dan cukup baik untuk digunakan karena kesederhanaan dan kemampuan implementasinya dalam berbagai metodologi statistika [2].

Sektor keuangan adalah salah satu sektor perusahaan yang ikut berperan aktif dalam pasar modal, karena sektor keuangan merupakan penunjang sektor rill dalam perekonomian Indonesia. Sekitar $87,1 \%$ dari total aset industri keuangan dikuasai oleh perbankan, jika terjadi krisis pada sektor perbankan maka akan terjadi krisis di sektor keuangan. Subsektor perbankan merupakan perusahaan yang saat ini banyak diminati para investor, karena return atas saham yang akan diperoleh menjanjikan [3].

Pada penelitian sebelumnya, dibahas mengenai model ARCH-GARCH yang digunakan untuk menganalisis volatilitas saham bluechips oleh Sholichah. Model ARCHGARCH tersebut kemudian digunakan dalam menghitung nilai Value at Risk (VaR) sehingga diperoleh nilai kerugian minimal saat berinvestasi pada saham tersebut [4]. Sedangkan pada penelitian yang dilakukan oleh Nurhidayah, perhitungan VaR dilakukan dengan menggunakan simulasi monte carlo pada model GARCH-mean [5].

Pada penelitian ini, dilakukan perhitungan estimasi risiko dengan menggunakan metode ARCH-GARCH pada data saham sektor keuangan. Selain itu digunakan simulasi monte carlo untuk mendapatkan hasil estimasi risiko yang lebih akurat.

\section{DASAR TEORI}

\section{A. Return Saham}

Jika $P_{t}$ adalah nilai saham pada periode ke-t dan $P_{t-1}$ adalah nilai saham pada periode ke-t-1, maka $R_{t}$ didefinisikan sebagai berikut [6]:

$$
R_{t}=\ln \left(\frac{P_{t}}{P_{t-1}}\right)=\ln \left[P_{t}\right]-\ln \left[P_{t-1}\right]
$$

\section{B. Identifikasi model ARIMA (Autoregressive Integrated} Moving Average)

Dasar pemikiran time series adalah pengamatan sekarang $\left(Z_{t}\right)$ tergantung pada 1 atau beberapa pengamatan sebelumnya $\left(Z_{t+k}\right)$. Model time series dibuat karena secara statistik ada korelasi antar deret pengamatan [7]. Model-model time series:

1. Autoregressive Model (AR)

Bentuk umum model autoregressive dengan orde $p$ (AR (p)) adalah:

$$
Z_{t}=\emptyset_{1} Z_{t-1}+\emptyset_{2} Z_{t-2}+\cdots+\emptyset_{p} Z_{t-p}+a_{t}
$$


dengan:

$\emptyset_{1}, \emptyset_{2}, \ldots, \emptyset_{p}$ : parameter-parameter autoregressive

$a_{t} \quad$ : nilai kesalahan pada waktu ke-t

2. Moving Average Model (MA)

Bentuk umum model moving average orde $q$ (MA $(q)$ ) adalah:

$$
Z_{t}=a_{t}-\theta_{1} a_{t-1}-\theta_{2} a_{t-2}-\cdots-\theta_{q} a_{t-q}
$$

dengan:

$\theta_{1}, \theta_{2}, \ldots . \theta_{q}$ : parameter-parameter moving average

$a_{t-q} \quad$ : nilai kesalahan pada saat $t-q$

3. Proses ARMA

Secara umum model ARMA $(p, q)$ adalah:

$Z_{t}=\emptyset_{1} Z_{t-1}+\cdots+\emptyset_{p} Z_{t-p}+a_{t}-\theta_{1} a_{t-1}-\cdots-\theta_{p} a_{t-q}$

4. Autoregressive Integrated Moving Average (ARIMA)

Proses ARIMA $(\mathrm{p}, \mathrm{d}, \mathrm{q})$ berarti suatu runtun waktu non stasioner yang setelah diambil selisih dari lag tertentu atau dilakukan differencing menjadi stasioner yang mempunyai model AR derajat $\mathrm{p}$ dan MA derajat $\mathrm{q}$. Model ARIMA (p,d,q) dinyatakan dalam rumus sebagai berikut :

dengan,

$$
a_{p}(B)(1-B)^{d} X_{t}=b_{0}+b_{q}(B)
$$

$a_{p} B=1-a_{1} B-\cdots-a_{p} B^{p}$, merupakan operator AR yang stasioner,

$b_{q} B=1-b_{1} B-\cdots-b_{q} B^{q}$, merupakan operator MA yang stasioner.

Untuk pendugaan model ARMA, data yang digunakan harus stasioner dalam mean maupun dalam varians. Lalu plot ACF dan PACF dilakukan untuk pendugaan orde model ARIMA, untuk estimasi parameter digunakan metode Least square. Setelah didapatkan nilai estimasi parameter dari persamaan model ARIMA $(p, d, q)$, langkah selanjutnya adalah melakukan pengujian signifikansi parameter dengan menggunakan Uji-t.

Hipotesis:

$H_{0}$ : estimasi parameter $=0$

$H_{1}$ : estimasi parameter $\neq 0$

Statistik uji:

$t_{\text {hitung }}=\frac{\text { estimasi parameter }}{\text { st.deviasi parameter }}$, st. dev $\neq 0$

Kriterian pengujian:

dengan menggunakan $\alpha=0.05$, jika $\left|t_{\text {hitung }}\right|>t_{\frac{\alpha}{2},(n-p-1)}$, maka $H_{0}$ ditolak artinya parameter model signifikan. Selain uji signifikan parameter model, dilakukan juga uji diagnostik residual bersifat white noise dan berdistribusi normal. Uji white noise,

Hipotesis:

$$
H_{0}: \rho_{1}=\cdots=\rho_{k}=0
$$

$H_{1}$ : minimal ada satu $\rho_{j} \neq 0$, dengan $j=1, \ldots, k$

Statistik uji:

$Q=n(n+2) \sum_{k=1}^{k} \frac{\hat{\rho}_{k}^{2}}{n-k}, \quad n>k$

Kriterian pengujian:

dengan menggunakan $\alpha=0.05$, jika $Q<\chi_{(\alpha ; k-p-q)}$, maka $H_{0}$ diterima artinya residual white noise. Uji distribusi normal,
Hipotesis:

$H_{0}: F(x)=F_{0}(x)$ untuk semua $x$ (berdistribusi normal)

$H_{1}: F(x) \neq F_{0}(x)$ untuk beberapa $x$ (tidak berdistribusi normal)

Statistik uji:

$D=\max \left|S(x)-F_{0}(x)\right|$

Kriteria pengujian:

dengan menggunakan $\alpha=0.05$, jika $D<D_{\alpha, n}$, maka $H_{0}$ diterima artinya residual model berdistribusi normal.

Untuk pemilihan model terbaik, dipilih berdasarkan model yang memiliki nilai AIC dan SIC terkecil.

\section{Model ARCH, GARCH,}

Secara umum, model ARCH, dan GARCH,

Model ARCH, dengan orde- $p$

$\sigma_{t}^{2}=\alpha_{0}+\alpha_{1} \varepsilon_{t-1}^{2}+\cdots+\alpha_{p} \varepsilon_{t-p}^{2}$

Model GARCH, dengan orde- $(p, q)$

$\sigma_{t}^{2}=\alpha_{0}+\alpha_{1} \varepsilon_{t-1}^{2}+\cdots+\alpha_{p} \varepsilon_{t-p}^{2}+\beta_{1} \hat{\sigma}_{t-1}^{2}+\cdots+\beta_{q} \hat{\sigma}_{t-q}^{2}$

Sebelum menentukan model ARCH dan GARCH terlebih dahulu dilakukan uji adanya unsur heterokedastisitas pada residual dari model ARIMA terbaik, menggunakan uji LjungBox.

Hipotesis:

$H_{0}$ : Tidak terdapat unsur ARCH-GARCH

$H_{1}$ : Terdapat unsur ARCH-GARCH

Statistik uji:

$L B=n(n+2) \sum_{k=1}^{m} \frac{\rho_{k}^{2}}{n-k}$

Kriterian pengujian:

dengan menggunakan $\alpha=0.05$, jika $L B>\chi_{\alpha, k-p-q}^{2}$ maka $H_{0}$ ditolak yang artinya ada unsur ARCH-GARCH [10].

Jika terdapat unsur heterokedastisitas, maka dilakukan plot ACF dari residual kuadrat untuk menentukan orde dari model ARCH dan GARCH. Untuk estimasi parameter digunakan metode Maksimum Likelihood. Uji signifikansi parameter model menggunakan uji-t dengan,

Hipotesis:

$H_{0}$ : estimasi parameter $=0$

$H_{1}$ : estimasi parameter $\neq 0$

Statistik uji:

$$
t_{\text {hitung }}=\frac{\text { estimasi parameter }}{\text { st.deviasi parameter }} \text {, st. dev } \neq 0
$$

Kriteria pengujian:

dengan menggunakan $\alpha=0.05$, jika $\left|t_{\text {hitung }}\right|>t_{\frac{\alpha}{2},(n-p-1)}$, maka $H_{0}$ ditolak artinya parameter model signifikan. Untuk pemilihan model terbaik dilihat dari model yang memiliki nilai AIC-SIC yang terkecil.

\section{Value at Risk (VaR)}

VaR adalah estimasi kerugian maksimum yang mungkin dialami dalam rentang waktu periode tertentu dengan tingkat kepercayaan tertentu (a given level of confidence). VaR biasanya ditulis dalam bentuk $\operatorname{VaR}(\alpha)$ atau $\operatorname{VaR}(\alpha, T)$ yang menunjukkan bahwa $\mathrm{VaR}$ bergantung pada nilai $\alpha$ dan $T$. Estimasi $\operatorname{Var}(\alpha)$ pada waktu $t$ hari adalah : 


$$
\operatorname{VaR}_{(1-\alpha)}(t)=W_{0} R^{*} \sqrt{t^{*}}
$$

\section{E. Simulasi Monte Carlo}

Penggunaan simulasi Monte Carlo untuk mengestimasi risiko telah diperkenalkan oleh Boyle pada tahun 1977. Dalam menghitung nilai $\mathrm{VaR}$ baik pada aset tunggal maupun portofolio, simulasi Monte Carlo mempunyai beberapa jenis algoritma. Namun pada intinya adalah melakukan simulasi dengan membangkitkan bilangan random berdasarkan karakteristik dari data yang akan dibangkitkan, kemudian digunakan dalam perhitungan VaR.

\section{METODOLOGI PENELITIAN}

Data yang digunakan dalam tugas akhir ini adalah data harga saham penutupan dari dua perusahaan yang termasuk dalam sektor keuangan khususnya sub sektor perbankan, yaitu Bank Central Asia Tbk dan Bank Negara Indonesia Tbk. Periode yang diambil yakni mulai 1 Januari 2015 hingga 28 Februari 2017.

Langkah pertama adalah plot time series dari data log return saham kedua perusahaan tersebut, lalu uji stasioneritas. Data yang telah stasioner dibuat plot ACF dan PACF untuk menetukan orde dari model ARMA. Setelah diperoleh dugaan model, dilakukan uji signifikansi, uji residual bersifat white noise dan berdistribusi normal. Untuk pemilihan model terbaik, dipilih berdasarkan nilai AIC-SBC terkecil.

Setelah mendapatkan model ARMA terbaik, dilakukan uji adanya pengaruh heterokedastisitas pada residual model tersebut, jika terdapat adanya unsur heterokedastisitas maka layak dilakukan pemodelan ARCH dan GARCH. Penentuan orde model ARCH, berdasarkan plot PACF dari residual kuadrat, lalu dilakukan uji signifikansi, dan penentuan model terbaik didasarkan pada nilai AIC-SIC yang terkecil.

Setelah mendapatkan model ARMA dan ARCH-GARCH, dilakukan perhitungan estimasi resiko dengan metode Value at Risk dan simulasi monte carlo.

\section{HASIL DAN PEMBAHASAN}

Data observasi pada subbab ini adalah harga saham penutupan harian dari Bank Central Asia Tbk dan Bank Negara Indonesia Tbk. pada periode mulai 1 Januari 2015 28 Februari 2017. Karakteristik data yang dianalisis merupakan data log return (Continously Compounded Return) harga saham penutupan.

\section{A. Pemodelan ARMA}

Langkah awal untuk menentukan model ARMA adalah plot grafik dari data penutupan saham dan data log return perusahaan.

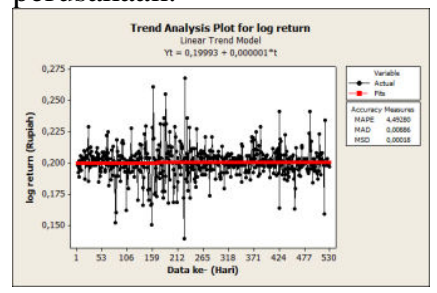

(a)

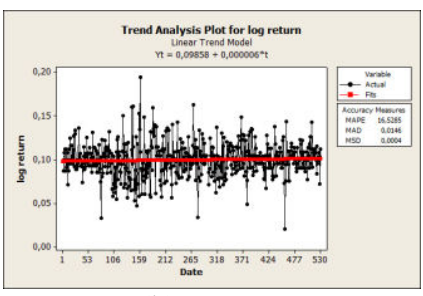

(b)

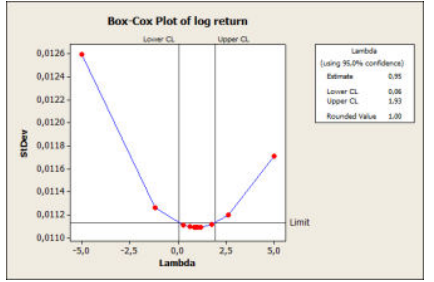

(a)

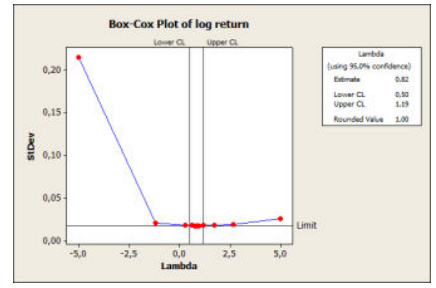

(b)
Gambar 2. Plot Box-Cox data log return saham (a) BBCA (b) BBNI

Gambar 1 dan Gambar 2 menunjukkan bahwa grafik log return saham telah stasioner dalam mean dan varian. Langkah selanjutnya adalah plot ACF dan PACF untuk menentukan orde dari model ARMA. Plot ACF dan PACF akan menunjukkan lag yang signifikan (keluar batas). Dari data BBCA lag yang keluar batas ada pada plot ACF lag ke-3,5, dan 32 dan pada plot PACF lag ke-3,5, dan 59, sehingga dugaan modelnya adalah ARMA([5,59],[3,4,32]), $\operatorname{ARMA}([3], 0), \operatorname{ARMA}([3],[32]), \operatorname{ARMA}([3],[3,32])$, dan $\operatorname{ARMA}([5],[32])$. Setelah didapatkan dugaan model selanjutnya dilakukan uji signifikansi, uji residual white noise, dan uji residual berdistribusi normal. Model terbaik dipilih berdasarkan nilai AIC-SIC yang terkecil. Langkah yang disama digunakan untuk pendugaan model pada saham BBNI. Tabel 1 menunjukkan hasil model ARMA terbaik dari kedua perusahaan tersebut.

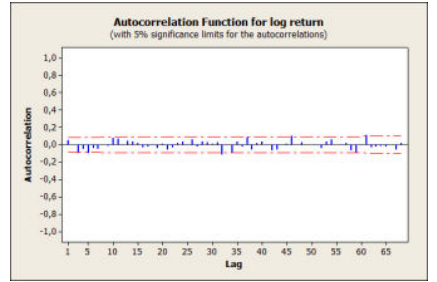

(a)

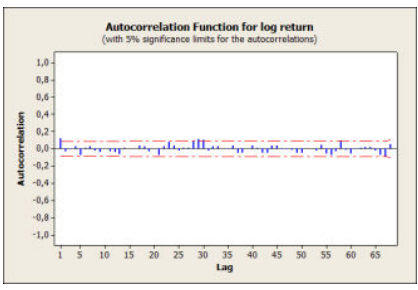

(b)

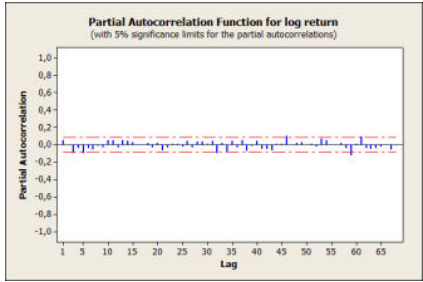

(a)

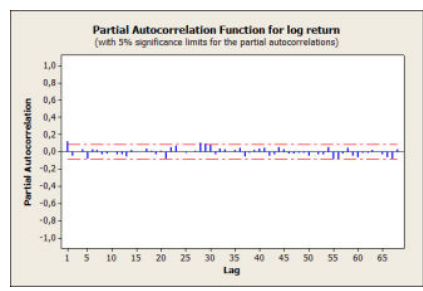

(b)
Gambar 3. Plot ACF dan PACF data log return saham (a) BBCA (b) BBNI.

Setelah dilakukan pengujian signifikansi, model ARMA yang memenuhi untuk BBCA adalah ARMA([3],[3,32]) dan untuk BBNI adalah ARMA([1],[28])

Tabel 1.

Uji Signifikansi model ARMA

\begin{tabular}{cccc}
\hline \hline Saham & Model & Parameter & Koefisien \\
\hline BBCA & ARMA & $\mathrm{C}$ & 0.200275 \\
& $([3],[3,32])$ & $\emptyset_{3}$ & 0.513985 \\
& & $\theta_{3}$ & -0.616391 \\
& & $\theta_{32}$ & -0.115608 \\
\hline BBNI & ARMA & $\mathrm{C}$ & 0.100113 \\
& $([1],[28])$ & $\emptyset_{1}$ & 0.103302 \\
& & $\theta_{28}$ & 0.101932 \\
\hline \hline
\end{tabular}

Gambar 1. Plot Time series data log return saham (a) BBCA (b) BBNI. 
Masing-masing model juga telah memenuhi asumsi residual white noise, untuk memilih model terbaik dipilih berdasarkan nilai AIC-SIC yang terkecil.

Tabel 2.

Uji residual white noise Model ARMA Terbaik

\begin{tabular}{ccccc}
\hline \multirow{2}{*}{ Lag } & \multicolumn{3}{c}{ BBCA } & \multicolumn{2}{c}{ BBNI } \\
\cline { 2 - 5 } & Q-Stat & $\chi^{2}{ }_{(0.05 ; k-p-q)}$ & Q-Stat & $\chi^{2}{ }_{(0.05 ; k-p-q)}$ \\
\hline 6 & 6.9764 & 7.81 & 5.3891 & 9.49 \\
12 & 12.386 & 16.92 & 7.9826 & 18.31 \\
\hline \hline
\end{tabular}

Tabel 3.

Model ARMA Terbaik

\begin{tabular}{cccc}
\hline \hline \multirow{2}{*}{ Saham } & Model & AIC & SIC \\
\hline BBCA & ARMA([3],[3,32]) & -5.80993 & -5.77749 \\
BBNI & ARMA([1],[28]) & -5.02110 & -4.99685 \\
\hline \hline
\end{tabular}

Pemodelan ARMA untuk Bank Central Asia Tbk. (BBCA) adalah model ARMA ([3],[3,32])

$$
\begin{aligned}
Z_{t}= & 0.200275+0.513985 Z_{t-3} \\
& -(-0.115608) a_{t-32}-(-0.616391) a_{t-3}
\end{aligned}
$$

Pemodelan ARMA untuk Bank Negara Indonesia Tbk. (BBNI) adalah model ARMA ([1],[28])

$$
Z_{t}=0.100113+0.103302 Z_{t-1}+a_{t}-0.101932 a_{t-28}
$$

\section{B. Pemodelan ARCH-GARCH}

Sebelum pemodelan ARCH-GARCH, terlebih dahulu dilakukan uji adanya unsur heterokedastisitas pada residual kuadrat model ARIMA terbaik.

Tabel 4.

Uji adanya unsur heterokedastisitas

\begin{tabular}{ccccc}
\hline \multirow{2}{*}{ Lag } & \multicolumn{3}{c}{ Uji adanya unsur heterokedastisitas } \\
\cline { 2 - 5 } & Q-Stat & $\chi^{2}{ }_{(0.05 ; k-p-q)}$ & Q-Stat & $\chi_{(0.05 ; k-p-q)}^{2}$ \\
\hline 6 & 78.670 & 7.811 & 26.186 & 9.49 \\
12 & 90.923 & 16.92 & 56.122 & 18.31 \\
18 & 97.663 & 25.00 & 75.341 & 26.30 \\
24 & 114.12 & 31.41 & 84.306 & 33.92 \\
\hline \hline
\end{tabular}

Karena nilai $Q-$ stat $>X_{0.05 ; k-p-q}^{2}$ sehingga dapat diartikan terdapat unsur heterokedastisitas sehingga data layak untuk dilakukan pemodelan ARCH-GARCH. Selanjutnya dilakukan plot PACF untuk menentukan orde dari model ARCHGARCH. (a)

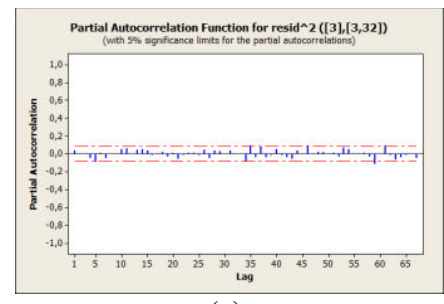

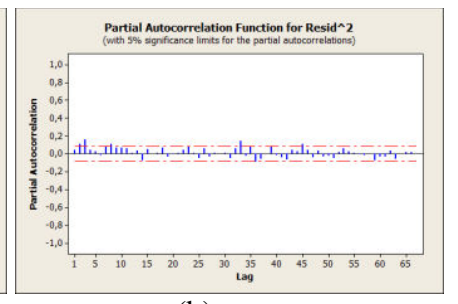

(b)
Gambar 4. Plot PACF residual kuadrat (a) BBCA (b) BBNI.

Berdasarkan plot PACF residual kuadrat dari Bank Central Asia Tbk lag yang keluar batas adalah pada lag ke-5 sehingga model yang memungkinkan adalah $\mathrm{ARCH}(5), \mathrm{ARCH}$ (1), GARCH $(1,1)$ atau $\operatorname{GARCH}(5,5)$ sedangkan untuk BBNI model yang memungkinkan adalah $\operatorname{ARCH}(3), \operatorname{ARCH}(1)$, GARCH $(1,1)$ atau $\operatorname{GARCH}(3,3)$. Dugaan model ini akan diestimasi parameter dan signifikansinya agar didapatkan model yang terbaik.

Sehingga didapatkan untuk BBCA adalah model mean $\operatorname{ARMA}([3],[3,32])$ dan model variannya $\mathrm{ARCH}(1)$ sedangkan untuk BBNI adalah model mean ARMA([1],[28]) dan model variannya $\mathrm{ARCH}(3)$.

Tabel 5.

Estimasi model ARCH-GARCH, Terbaik

\begin{tabular}{cccc}
\hline \hline Saham & Model & Parameter & Koefisien \\
\hline \multirow{3}{*}{ BBCA } & & $\mathrm{C}$ & 0.200392 \\
& & $\emptyset_{3}$ & 0.465777 \\
& & $\theta_{3}$ & -0.517608 \\
& & $\theta_{32}$ & -0.139383 \\
& ARCH ([3],[3,32]) & $\alpha_{0}$ & 0.000113 \\
& & $\alpha_{1}$ & 0.351759 \\
\hline \multirow{3}{*}{ BBNI } & \multirow{2}{*}{ ARMA ([1],[28]) } & $\emptyset_{1}$ & 0.100821 \\
& & $\theta_{28}$ & 0.096655 \\
& & $\alpha_{0}$ & 0.075825 \\
& ARCH(3) & $\alpha_{1}$ & 0.000235 \\
& & $\alpha_{2}$ & 0.153624 \\
& & $\alpha_{3}$ & 0.111070 \\
\hline \hline
\end{tabular}

Model mean dan varian yang sesuai untuk Bank Central Asia Tbk adalah model ARMA ([3],[3,32]) dan ARCH(1)

$Z_{t}=0.200392+0.465777 Z_{t-3}-(-0.517608) e_{t-3}-$ $(-0.139383) e_{t-32}$

$\sigma_{t}^{2}=0,000113+0.351759 \varepsilon_{t-1}^{2}$

Model mean dan varian yang sesuai untuk Bank Negara Indonesia Tbk adalah model ARMA ([1],[28]) dan ARCH(3)

$Z_{t}=0.100821+0.096655 Z_{t-1}-(-0.075825) a_{t-28}$ $\sigma_{t}^{2}=0.000235+0.153624 \varepsilon_{t-1}^{2}+0.140282 \varepsilon_{t-2}^{2}+$ $0.111070 \varepsilon_{t-3}^{2}$

\section{Perhitungan VaR (Value at Risk)}

Setelah didapatkan model mean dan varian untuk masing-masing saham, dilakukan estimasi risiko menggunakan Value at Risk

1. Bank Central Asia Tbk

Berdasarkan persamaan model mean dan persamaan varian BBCA, selanjutnya akan dihitung estimasi risiko dengan simulasi monte carlo.

Perhitungan estimasi risiko dengan menggunakan simulasi monte carlo pada saham Bank Central Asia mengahasilkan rata-rata nilai VaR sebesar $\mathrm{Rp}$ 21.181.676,00. Hal ini dapat diartikan dengan tingkat keyakinan $95 \%$ bahwa kerugian maksimum yang mungkin akan diterima investor dari dana yang telah diinvestasikan sebesar Rp 100.000.000, adalah Rp 21.181.676,00. dalam jangka waktu 24 jam kedepan.

2. Bank Negara Indonesia Tbk.

Berdasarkan persamaan model mean dan persamaan varian BBNI, selanjutnya akan dihitung estimasi risiko dengan simulasi monte carlo.

Perhitungan estimasi risiko dengan menggunakan simulasi monte carlo pada saham Bank Negara Indonesia Tbk mengahasilkan rata-rata nilai VaR sebesar Rp 13.165.936,00. Hal ini dapat diartikan dengan tingkat keyakinan $95 \%$ bahwa 
kerugian maksimum yang mungkin akan diterima investor dari dana yang telah diinvestasikan sebesar $\mathrm{Rp} 100.000 .000$, adalah Rp 13.165.936,00 dalam jangka waktu 24 jam kedepan.

\section{KESIMPULAN}

Berdasarkan dari hasil analisa data log return pada harga saham dari Bank Central Asia Tbk. dan Bank Negara Indonesia Tbk. dapat diambil kesimpulan sebagai berikut:

1. Pada saham Bank Central Asia Tbk didaptkan model mean yang memenuhi adalah ARIMA ([3],[3,32]) dan model varian yang memenuhi ARCH(1), bentuk modelnya adalah $Z_{t}=0.200392+0.465777 Z_{t-3}-(-0.517608) e_{t-3}-$

$$
\begin{gathered}
(-0.139383) e_{t-32} \\
\sigma_{t}^{2}=0,000113+0.351759 \varepsilon_{t-1}^{2}
\end{gathered}
$$

Pada saham Bank Negara Indonesia Tbk didaptkan model mean yang memenuhi adalah ARIMA ([1],[28]) dan model varian yang memenuhi $\mathrm{ARCH}(3)$, bentuk modelnya adalah $Z_{t}=0.100821+0.096655 Z_{t-1}-(-0.075825) a_{t-28}$

$$
\begin{gathered}
\sigma_{t}^{2}=0.000235+0.153624 \varepsilon_{t-1}^{2}+0.140282 \varepsilon_{t-2}^{2}+ \\
0.111070 \varepsilon_{t-3}^{2}
\end{gathered}
$$

2. Estimasi resiko yang didapatkan jika menginvestasikan dana sebesar Rp. 100.000.000 dengan $\alpha=5 \%$, untuk
Bank Central Asia adalah Rp 21.181.676,00 ini berarti kemungkinan kerugian maksimum yang diterima investor dari dana yang diinvestasikan sebesar Rp 21.181.676,00 dalam 24 jam kedepan, sedangkan untuk kerugan maksimumb saat investasi di Bank Negara Indonesia Tbk adalah Rp 13.165.936,00

\section{DAFTAR PUSTAKA}

[1] W. Nastiti, "Estimasi Risiko Investasi Saham Perusahaan Sektor Telekomunikasi di Bursa Efek Indonesia Menggunakan Metode Conditional Value at Risk dan Value at Risk Dengan Pendekatan ARMAGARCH dan Extreme Value Theory," Surabaya, 2016.

[2] H. Situngkir, "Value at Risk yang memperhatikan sifat Statistika Distribusi return," Bandung.

[3] N. W. Liyandani and S. Dewi, "Dampak Struktur Modal dan Inflasi Terhadap Profitabilitas dan Return Saham Perusahaan Keuangan Sektor Perbankan," Bali, 2016.

[4] I. Sholichah, "Analisis Volatilitas dan Value at Risk Pada Saham Bluechips," Surabaya, 2014.

[5] A. R. Nurhidayah, "Simulasi Monte Carlo Untuk Perhitungan Value at Risk Pada Model GARCH-mean," Malang, 2016.

[6] E. Tandelilin, "Analisis Investasi dan Managemen Portofolio," Yogyakarta, 2001.

[7] W. W. S. Wei, Time Series Analysis Univariate and Multivariate Methods. Pearson Education, Inc, 2006. 